\title{
Relationship of resistance to sudden death syndrome with yield and other important agronomic traits in a recombinant inbred soybean population
}

\author{
James Anderson ${ }^{1}$, W. Clark ${ }^{1}$, M. Humberto Reyes-Valdes ${ }^{2}$, Stella K. Kantartzi ${ }^{1}$, \\ ${ }^{1}$ Department of Plant and Soil Sciences, Southern Illinois University, Carbondale, IL USA \\ ${ }^{2}$ Department of Plant Breeding, Universidad Autónoma Agraria Antonio Narro, Saltillo, Coah., Mexico
}

Email address:

kantart@siu.edu (S. K. Kantartzi)

\section{To cite this article:}

James Anderson, W. Clark, M. Humberto Reyes-Valdes, Stella K. Kantartzi. Relationship of Resistance to Sudden Death Syndrome with Yield and other Important Agronomic Traits in a Recombinant Inbred Soybean Population. Journal of Plant Sciences.

Vol. 3, No. 1, 2015, pp. 22-26. doi: 10.11648/j.jps.20150301.14

\begin{abstract}
The objective of this study was to evaluate a recombinant inbred line population derived from a cross between a recombinant inbred line (RIL) resistant to sudden death syndrome (SDS). 'LS90-1920' with a susceptible line, 'Spencer' in order to identify any significant association between yield and important agronomic traits with SDS, estimate heritability of these traits and determine whether there are traits that can be used as predictors for SDS resistance. Correlation coefficients for yield and agronomic traits (maturity, lodging, and plant height) were moderately to highly significant but there was no significant association between these traits and SDS resistance. Genotype by environment interaction was significant for all traits studied except of plant height. Maturity, lodging, plant height and SDS resistance were moderately to highly heritable whereas yield showed very low heritability. Our findings showed that environment plays a very crucial role in selection. It is showed that genotypic selection can speed up but cannot replace phenotypic selection across environments and time. Environment is important for the development and production of crop plants because it optimizes the association between the genotype and the phenotype. Highlights: Created Recombinant Inbred Line; Tested for agronomic traits including yield; Tested for disease resistance; Analyzed results to determine if Recombinant Inbred Line differed from the parental lines; Determined if traits were inherited from parents.
\end{abstract}

Keywords: Soybean, Recombinant Inbred Line, Sudden Death Syndrome, Plant Height, Lodging, Yield

\section{Introduction}

Soybeans [Glycine $\max$ (L.) Merr.] are an important agronomic crop with worldwide production topping two hundred and fifty million metric tons [1]. Plant yield is the most important characteristic for soybeans but at the same time, there is a clear need to prevent losses due to disease. In 2009 there was an estimated loss of over nine hundred thousand metric tons of soybeans due to SDS caused by Fusarium verguliforme [2]. Because of this high loss of yield, a conceited effort must be undertaken in order to minimize the loss.

Yield loss due to SDS tends to be either pre-emergence or post-emergence [3]. Pre-emergent SDS can be treated via a seed treatment in order to minimize yield loss [4]. However, due to the environmental factors that play into the post-emergence appearance of SDS, it is easier to have resistant parents than to deal with spray fields with fungicide. The categorization of soybean lines for SDS resistance is also vital due to the high number of new lines of soybeans released each year [5, 6]. Symptoms of SDS post-emergence affect the leaf, forming a necrosis on the leaf. Therefore, it is important to understand how SDS interacts with agronomic traits. By understanding how the disease interacts with agronomic traits we can better understand how SDS affects crop yield and agronomic traits.

Njiti et al [7] described a method for determining the reaction of plants to SDS disease symptoms by looking at a combination of two factors, disease incidence and disease severity and using them for calculating disease index (DX) [7]. This method ensures that lines have resistance to SDS, as heavy disease presence can affect yield [8]. It was shown that agronomic traits have either a positive or negative correlation to yield [9]. A better understanding of the effect of SDS on 
agronomic traits will allow for a better management practices for fields. Similarly, the interaction of agronomic traits and how they affect each other is also a vital understand how they affect the recombinant inbred line (RIL) [10].

Study of quantitative traits is challenging because they are affected by environmental conditions and their heritability is reduced, facts that makes genetic improvement difficult [11]. Thus, correlation studies are important because they bring up hidden genetic patterns and interrelationship of quantitative traits. Results of these studies can be useful for designing successful breeding programs and helpful for trait evaluation and selection.

The objectives of this study were to use a RIL population ( $n=94)$ derived from a cross between a high-yield line resistant to SDS, 'LS90-1920' with a susceptible line, 'Spencer' to (i) identify any significant association between yield and important agronomic traits with SDS (ii) estimate heritability of these traits and (iii) determine whether there are traits that can be used as predictors for SDS resistance.

\section{Material and Methods}

\subsection{Plant Material and Field Evaluation}

Ninety-four RIL lines were developed from a cross of LS90-1920 and Spencer that was made in 2002 at Agriculture Research Center of Southern Illinois University in Carbondale, IL. The LS90-1920 soybean line was released in 1996 because of its high yield and its resistance to SDS [12]. The soybean line Spencer [13] is a line that used as a check in SDS studies because it is highly vulnerable to $F$. virguliforme. The lines were advanced to the $F_{6}$ generation without any selection using single-pod descent method [14]. The $F_{6}$ and $F_{7}$ generation were evaluated for their yield performance and data for agronomic traits (maturity, lodging and plant height) were collected in 2011 across two locations in southern Illinois (Dowell and Harrisburg).

Reaction to SDS was scored in comparison to LS90-1920, Spencer, and 'Ripley' (PI 536636; [15]; resistant check) for two years (2010 and 2011) in Carbondale and Valmeyer, IL. The SDS evaluation method used was the same as was described by Njiti et al. [7], which uses the formula DI*DS/9 to calculate DX. DI is the SDS disease incidence recorded per plot as the percentage of plants showing visible leaf symptoms and DS is the disease severity that was rated only from plants that showed symptoms, following a scale from 1 to 9 $(1=0-10 \%$ death of the plant with $1-5 \%$ of leaf area necrotic/chlorotic, $2=10-20 \%$ death of the plant with $6-10 \%$ of leaf area necrotic/chlorotic, $3=20-40 \%$ death of the plant with $10-20 \%$ of leaf area necrotic/chlorotic, $4=40-60 \%$ death of the plant with $20-40 \%$ of leaf area necrotic/chlorotic, $5=$ Over $60 \%$ death of the plant with over $40 \%$ of leaf area necrotic/chlorotic, $6=\mathrm{Up}$ to $33 \%$ of leaf loss due to premature defoliation, $7=$ Between $33 \%$ and $66 \%$ leaf loss due to premature defoliation, $8=$ Over $66 \%$ leaf loss due to premature defoliation, and 9=premature death). Relative resistance (RR) is calculated as the percentage of the susceptible check's (Spencer) DX (RR=DX of line/DX of Spencer $x$ 100). RR is useful in statistical analysis because it allows the comparison of lines across different environments.

In all experiments, RIL population along parent lines were planted in randomized complete block designs with two blocks. Plots were 2 rows wide and $6 \mathrm{~m}$ long, with $0.76-\mathrm{m}$ space between rows. Seed yield was expressed as $\mathrm{kg} \mathrm{ha}^{-1}$. Data for maturity were collected when approximately $95 \%$ of the pods in a plot had reached mature color (R8; [16]) after September 1. Lodging was rated at maturity using a scale from 1 to 5 , where 1 means that all plants standing erect and 5 that all plants prostrate. Plant height is expressed in $\mathrm{cm}$.

\subsection{Statistical Analysis}

The mean, standard deviation, and Shapiro-Wilks test for normality was analyzed using JMP 11 (SAS Institute, Cary, NC). Means, standard deviations, Pearson's coefficient and regression with multiple predictors were calculated from RIL lines and their parents from collected data. The broad sense heritability of the RR was determined from the analysis of variance (ANOVA) where years and locations were treated as random effects. Broad sense heritability was calculated using the website pbstat.

\section{Results}

\subsection{Comparision of RIL and Parents}

Table 1. Mean values, standard deviation, coefficient of variance, and Shapiro-Wilks test for normality for SDS relative resistance (RR), yield, maturity, plant height and lodging of LS90-1920x Spencer recombinant inbred lines (RIL) and parental lines.

\begin{tabular}{|c|c|c|c|c|c|c|c|}
\hline \multirow{3}{*}{ Trait } & \multicolumn{3}{|c|}{ RIL (n=94) } & \multicolumn{4}{|l|}{ Parents } \\
\hline & \multirow{2}{*}{ Mean } & \multirow{2}{*}{ SD } & \multirow{2}{*}{$\mathbf{P}<\mathbf{W} \S$} & \multicolumn{2}{|c|}{ LS90-1920 } & \multicolumn{2}{|l|}{ Spencer } \\
\hline & & & & Mean & SD & Mean & SD \\
\hline RR (\%) & $18.8 \mathrm{a}$ & 18.8 & $<0.001$ & $8.8 \mathrm{a}$ & 8.3 & $36.7 b$ & 27.3 \\
\hline Yield $\left(\mathrm{kg} \mathrm{ha}^{-1}\right)$ & $2679.6 \mathrm{a}$ & 472.1 & 0.7265 & $3085.6 \mathrm{a}$ & 411.6 & $2407.5 b$ & 379.2 \\
\hline Maturity ${ }^{\dagger}$ & $39.6 b$ & 6.8 & $<0.001$ & $38.0 \mathrm{~b}$ & 4.0 & $29.1 \mathrm{a}$ & 2.4 \\
\hline Plant Height (cm) & $47.1 \mathrm{a}$ & 10.2 & $<0.001$ & $33.3 b$ & 5.9 & $40.1 b$ & 2.9 \\
\hline
\end{tabular}

† Days after September 1 when $95 \%$ of the pods reached their mature pod color (R8)

$\$ 1=$ all plants standing erect; $5=$ plots with all plants prostrate

$\S \mathrm{P}<\mathrm{W}$ Shapiro-Wilk test for normality

- Same letter connect values with no significant differences at $\mathrm{P}<0.05$ in the same line 
The mean, standard deviation, and Shapiro-Wilks test for normality of the RR, yield, maturity, plant height, and lodging were measured for RIL and compared against LS90-1920 and Spencer (Table 1). Significant differences were found between Spencer and RIL for RR, yield, plant height, lodging and maturity. There were significant differences between LS90-1920 and RIL for plant height (Table 1). The distribution was significantly different from normal for RR, maturity, plant height, and lodging (Table 1). Also, there was no significant difference of normality for yield (Table 1).

\subsection{Analysis of Variance and Heritability}

A summary of ANOVA and broad sense heritability estimates for RR, yield, maturity, plant height, and lodging are presented in Table 2. There were significant differences between 94 RIL for all agronomic traits $(\mathrm{P}<0.01)$. All the traits, except of plant height had significant differences $(\mathrm{P}<0.01)$ in the interaction of RIL and testing locations. As for RR, differences between RIL and in the interaction of the year and location were also significant at $\mathrm{P}<0.01 * *$.

Broad sense heritability for RR was determined across locations and time of testing using ANOVA results (Table 2). Broad sense heritability of RIL for RR (62\%), plant height $(85 \%)$, maturity $(95 \%)$ and lodging $(84 \%)$ showed that these traits are controlled by genetics more than environmental components. Broad sense heritability for yield was very low $(2 \%)$ which means that is highly influenced by the environment.

Table 2. Summary of ANOVA table and broad sense heritability estimates for $S D S$ relative resistance (RR), yield, maturity, plant height and lodging of LS90-1920x Spencer recombinant inbred lines (RIL).

\begin{tabular}{lllll}
\hline Trait & Genotype (G) & Location (L) & G x L & $\boldsymbol{H}^{\mathbf{2}}$ \\
\hline RR $(\%)$ & $* *$ & $* *$ & $* *$ & 0.62 \\
Yield $\left(\mathrm{kg} \mathrm{ha}^{-1}\right)$ & $* *$ & $* *$ & $* *$ & 0.02 \\
Maturity & $* * \dagger$ & $* *$ & $* *$ & 0.95 \\
Plant Height $(\mathrm{cm})$ & $* *$ & $\mathrm{~ns}$ & $\mathrm{~ns}$ & 0.85 \\
Lodging & $* * \dagger$ & $* *$ & $* *$ & 0.84 \\
\hline
\end{tabular}

* = significant at $\mathrm{P}<0.05$

$* *$ = significant at $\mathrm{P}<0.01$

$* * *=$ significant at $\mathrm{P}<0.001$

ns $=$ not significant

$\dagger$ Days after September 1 when $95 \%$ of the pods reached their mature pod color (R8)

$\$ 1=$ all plants standing erect; $5=$ plots with all plants prostrate

$\S$ Broad sense heritability (\%) estimated from ANOVA

\subsection{Correlations Coefficients}

Pearson's coefficient was determined to the relationship between RR, yield, maturity, plant height, and lodging for RIL population (Table 3 ). The highest relationship was found between plant height and lodging $(r=0.6079 * * *)$ and the lowest relationship that was still significantly different was between lodging and yield $\left(r=0.2276^{* * *}\right)$. Moderate but significant was correlation between yield with maturity $\left(r=0.5028^{* * *}\right)$, yield with plant height $\left(r=0.3508^{* * *}\right)$, maturity with plant height $(r=0.5403 * * *)$ and maturity with lodging $\left(r=0.4911^{* * *}\right)$. No significant was identified between $\mathrm{RR}$ and yield or other agronomic traits.

Table 3. Correlation coefficients for SDS relative resistance (RR), yield, maturity, plant height and lodging of LS90-1920 x Spencer recombinant inbred lines (RIL).

\begin{tabular}{lllll}
\hline Trait & Maturity & Lodging & Yield & RR \\
\hline Plant height & $0.5043^{* * *}$ & $0.6079 * * *$ & $0.3508^{* * *}$ & $0.1386^{\text {ns }}$ \\
Maturity & & $0.4911^{* * *}$ & $0.5028^{* * *}$ & $0.0624^{\text {ns }}$ \\
Lodging & & & $0.2276^{* *}$ & $0.1214^{\text {ns }}$ \\
Yield & & & $0.0215^{\text {ns }}$ \\
\hline$*$ = significant at $\mathrm{P}<0.05$ & & \\
$* *=$ significant at $\mathrm{P}<0.01$ & & \\
$* * *=$ significant at $\mathrm{P}<0.001$ & & \\
ns = not significant & & \\
\end{tabular}

\section{Discussion}

In this study we analyzed data for SDS resistance using the method as described by Njiti et al. [7] in combination with agronomic characteristics included yield, maturity, lodging and plant height in a RIL population from the cross LS90-1920 and Spencer. The parental lines were chosen for their significantly different reaction to SDS. LS90-1920 was released and registered for its resistance to SDS [12] while Spencer is used as susceptible check to most SDS experiments [17].

The RR for RIL was significantly lower than the susceptible parent, but had no significantly differences than the resistant parent (Table 1). This shows that the RIL retained the resistant characteristic. More that $50 \%$ of RIL inherited the resistance trait from LS90-1920. This appears to be the case, as the broad sense heritability shows that $61 \%$ of RIL would have inherited the resistance (Table 2). However, there was no significant relationship between RR and any of the agronomic traits (Table 3). Since RR has no direct connection to the agronomic traits, than selections can be made for more disease resistant individuals without having to worry about the affect that it will have on the agronomic traits in the soybeans.

Yield for RIL differed significantly from the parental line Spencer (Table 1). Lodging of RIL did not differ significantly from LS90-1920 but was significantly different than Spencer (Table 1). Plant height was both significantly different and higher from both parents (Table 1). Maturity for RIL was not significantly different from the LS90-1920, but was significantly different than the Spencer (Table 1). The mean values for the RIL for RR, yield, and maturity were either between the mean values of the parents or not significantly different from the upper value (Table 1). The mean values for RIL agronomic traits for plant height and lodging were higher than the parents. (Table 1)

There was a very high genotype by environment interaction for yield (Table 2). Similar results were reported for traits as yield, maturity and plant height in soybean from other researchers that identified the effect of environment to genotype and their strong interaction $[18,11]$. This indicates that a line can only produce significant yield when both genotype and environment are favorable. 
Even though there were significant differences for yield between RIL and parents, heritability was very low (Table 2). When yield is analyzed for variance components, environmental effects are considered random. The genotype by location effect was highly significant, with a large mean square, and this was a major contributing factor for the low heritability. However, when environments were treated as fixed effects, yield differences became significant. Therefore, it can be concluded that there were significant differences for genetic effects, but only under the particular conditions of evaluation. All other agronomic traits that were tested showed a moderate to high heritability, as shown in Table 2.

Significant correlations were identified between yield and agronomic traits (plant height, maturity, and lodging) as presented in Table 3. Significant correlations of agronomic traits, both positive and negative were reported previously in soybean $[19,11]$. In our study, strong positive correlation $(0.5028 * * *)$ between maturity and yield is reasonable, as the longer a plant has to mature, the more it will yield. Similarly, a moderate positive correlation $\left(0.3508^{* * *}\right)$ between plant height and yield is also reasonable while a taller plant overall will be more productive. Yield and lodging had a weak positive correlation $(0.2276 \mathrm{~ns})$. Increased weight on soybean may increase the weight on the plant and subsequently increase the lodging score. The reason this may be not significant is due to the loss of yield due to the increased lodging.[20] However, because there is a strong positive correlation $(0.6079 * * *)$ between lodging and plant height, as well as the moderate correlation between height and yield described before, some of the lower values of correlation between lodging and yield may be explained. Increased height causes more lodging as well as higher yield, however, the higher plants cause increased lodging, which can lower yield recovered from plants [20]. The strong positive correlation $\left(0.4911^{* * *}\right)$ between lodging and maturity would indicate that the more lodged a plant would become the longer it would take to mature. Strong positive correlation between plant height and maturity $\left(0.5043^{* * *}\right)$ would indicate that a taller plant would take longer to mature. This makes sense, since a taller plant would have more leaves and therefore take longer to mature.

However, when an analysis of the interaction between plant height, maturity, and lodging was done using regression with multiple predictors, the interaction between height and lodging and maturity and lodging is significant at $\mathrm{P}<0.001$, but the interaction of all three is not significant at $\mathrm{P}<0.05$. This shows that, while the agronomic traits are correlated together, there is no connection linking all the traits at the same time.

In crop breeding, yield is considered as the absolute priority when selecting for new lines. Because of this, yield should be valued over other agronomic traits. Although other traits are not as important, they should not be disregarded as traits that are more helpful to the grower can be helpful as well.

Absence of significant correlation between yield and SDS resistance shows that selecting both traits is strenuous. Our research in this RIL population showed that environment plays a very crucial role in selection. Once more, it is showed that genotypic selection can accelerate but cannot replace phenotypic selection across environments and time. Environment is important for the development and production of crop plants because it optimizes the association between the genotype and the phenotype (Prof. Fasoulas, 2006, personal communication).

\section{References}

[1] T. Masuda, P. D. Goldsmith, World soybean production: Area harvested, yield and long-term projections. International food and agribusiness management review 12 (9): 143-162, 2009

[2] S. R. Koenning, N. Carolina, P. O. Box, J.A. Wrather, Suppression of soybean yield potential in the continental United States by plant diseases from 2006 to 2009 Plant health progress plant health progress doi:10.1094 /PHP-2010-1122-01-RS , 2010

[3] N. Hnetkovsky, S. J. C. Chang, T. W. Doubler, P. T. Gibson, D. A. Lightfoot, Genetic mapping of loci underlying field resistance to soybean sudden death syndrome (SDS). Crop Science 400: 393-400, 1996

[4] G. L. Hartman, G. R. Noel, L. E. Gray, Occurrence of soybean sudden death syndrome in east-central Illinois and associated yield losses. Plant Disease 79: 314-318, 1995

[5] S. K. Kantartzi, J. Klein and M. Schmidt, Registration of 'Saluki 4411' soybean with resistance to sudden death syndrome and HG Type 0 (Race 3 ) soybean cyst nematode Journal of Plant Registration 6:298-301, 2012

[6] S. K. Kantartzi, J. Klein and M. Schmidt, Registration of 'Saluki 4910' soybean [Glycine max (L.) Merr.] with high yield potential and resistance to multiple diseases Journal of Plant Registration 7:31-35, 2013

[7] V. N. Njiti, R. J. Suttner, L. E. Gray, P. T. Gibson, D. A. Lightfoot, Rate-reducing resistance to Fusarium solani $f s p$. phaseoli underlies to soybean sudden death syndrome field resistance in soybean because of SDS caused by the fungus $F$. solani. field. Crop Science 37: 132-138, 1996

[8] S. J. Chang, C. Doubler, T. W. Kilo, V. Y. Abu-Thredeih, J. Prabhu, R. Freire, R. Suttner, M. E. Schmidt, P. T. Gibson, D. A Lightfoot, Association of loci underlying field resistance to soybean sudden death syndrome (SDS) and cyst nematode (SCN) Race 3. Crop Science 37: 965-971, 1997

[9] D. R. Panthee, V. R. Pantalone, M. Saxton, D. R. West, C. E. Sams, Quantitative trait loci for agronomic traits in soybean. Plant Breeding 126 (1): 51-57, 2007

[10] I. Sherrie, O. Khaled, E. Washington, P. Lage, S. Woods, S. K. Kantartzi, M. A. Kassem, Evaluation of several agronomic traits in 'Essex' by 'Forrest' recombinant inbred line population of soybean [Glycine max (L.) Merr.]. Atlas Journal of Plant Biology 1(1): 13-17, 2011

[11] M. S. Cicek, P. Chen, M. A. Saghai Maroof, G. R. Buss, Interrelationships among agronomic and seed quality traits in an interspecific soybean recombinant inbred population. Crop Science 46:1253-1259, 2006

[12] M. E. Schmidt, J. H. Klein, R. J. Suttner, O. Myers Jr, Registration of LS90-1920 soybean. Crop Science 39: 295, 1999 
[13] J. R. Wilcox, M. T. Roach, T. S. Abney, Registration of 'Spencer' soybean. Crop Science 29: 830-831, 1989

[14] W. R. Fehr, Principles of cultivar development. Macmillan, New York, 1991

[15] R. L. Cooper, R. J. Martin, B. A. McBlain, R. J. Fioritto, S. K. St. Martin, A. Calip-DuBois, A. F. Schmitthenner, Registration of 'Ripley' soybean. Crop Science 30:963, 1990

[16] W. R. Fehr, C. E. Caviness, D. T. Burmood, J. S. Pennington, Stage of development descriptions for soybeans, Glycine max (L.) Merr. Crop Science 11:929-931, 1971

[17] W. D. Clark, M. H. Reyes-Valdes, J. Bond, S. K. Kantartzi, Performance of LS97-1610 x 'Spencer' soybean recombinant inbred line population segregating for resistance to Fusarium virguliforme. Canadian Journal of Plant Science 93(6): $1179-1185,2013$

[18] W. G. Chandler, W. R. Fehr, L. A. Wilson, Association of soybean seed traits with physical properties of natto. Crop Science 40: 1529-1534, 2000

[19] A. Kumar, V. Pandley, M. Kumar, A. M. Shehh, Correlation study in soybean [Glycine $\max (\mathrm{L}$.$) Merr] with response to$ prevailing weather parameter, agro-meteorological indices to seed and stover yield at Anand. American-Eurasian Journal of Agronomy 1 (2): 31-33, 2008

[20] C.R. Weber and W.R. Fehr, Seed yield losses from lodging and combine harvesting in soybeans. Agronomy Journal 58 (3) 287-289, 1966 